\title{
MAGNETIC RESONANCE ENTEROGRAPHY: AN EMERGENT TECHNIQUE FOR CHARACTERIZATION OF SMALL BOWEL LESIONS IN ONCOLOGICAL AND NON-ONCOLOGY DISEASES
}

\author{
Waqas Ahmad ${ }^{1}$, Iram Zaheer ${ }^{2}$, Imran K. Niazi ${ }^{1}$, Khurram A. Mufti ${ }^{3}$ \\ ${ }^{1}$ Department of Radiology, Shaukat Khanum Memorial Cancer Hospital and Research Centre, Lahore, Pakistan, \\ 2Department of Medical Imaging, Armed Forces Hospital, King Abdul Aziz Naval Base, Jubail, Kingdom of Saudi \\ Arabia, ${ }^{3}$ Department of Diagnostic Imaging, The Prince Charles Hospital, Brisbane, Australia
}

Received: 16 October 2018 / Accepted: 6 December 2018

\begin{abstract}
Small bowel is not easily accessed by endoscope and diagnosis of its pathology relies on clinical assessment and imaging. Traditional contrast studies have the disadvantage of not including the mural and extramural details. This is best seen with magnetic resonance enterography (MRE) which is rapidly replacing computed tomography enterography due to better soft tissue resolution and lack of ionizing radiation. Comprehensive MRE requires axial and coronal T1- and T2-WI, high-resolution diffusion-weighted images, fat-suppressed three-dimensional T1-W breath-hold gradient-echo images of the abdomen, and pelvis before and after intravenous gadolinium-based contrast material administration. MRE is the preferred imaging technique for small bowel pathology due to its ability to show mural and extramural details which allow differentiation in acute, active, and chronicity of changes. Being radiation free, there is no age limitation for its use.
\end{abstract}

Key words: Breast cancer, colorectal cancer, hematological malignancies, immunotherapy, Indoleamine 2,3-dioxygenase, pancreatic cancer, prostate cancer

\section{Introduction}

Over the past few decades, the advancements in the field of computed tomography (CT) and magnetic resonance imaging have made it possible to evaluate the small bowel pathologies with more precision. Although CT enterography remained preferred technique for evaluation of small bowel due to its better visualization of the luminal and extraluminal disease process as compared to conventional fluoroscopic studies, ${ }^{[1,2]}$ the associated high ionization dose remains one of the major limitations.

Most patients requiring small bowel assessment fall in the category of younger age group having inflammatory bowel diseases. In such patients, imaging is required very often to see the disease activity, progress, response to treatment as well as associated complications. ${ }^{[3]}$ The other group would include patients with polyposis syndromes, who

Correspondence: Dr. Waqas Ahmed, Department of

Radiology, Shaukat Khanum Memorial Cancer Hospital and

Research Centre, Lahore. Pakistan.

Email:waqasrad@gmail.com would also be benefited with MR enterography (MRE) for detection and chronic surveillance. ${ }^{[4-7]}$

Emerging MRE is one of the promising modalities for such patients due to its various advantages over CT enterography. These include no risk of ionizing radiations exposure, its better contrast resolution and safer intravenous (IV) contrast agent. Furthermore, MRE can also provide the opportunity for functional assessment of bowel in term of its peristaltic activity and distensibility, especially in area of luminal strictures or narrowing using multiphasic dynamic sequences. MR has also benefit over $\mathrm{CT}$ in patients who have contraindication for contrast-enhanced CT scan, for example, pregnant patients and those who have are allergic to iodinated contrast media.

There are a few disadvantages of MRE as well; the cost and availability of the procedure would be the most significant limiting factor. The other drawbacks would include lack of expertise in performing and interpreting these procedures. Furthermore, in comparison to CT enterography especially the MIP imaging the spatial 
resolution would be lower and acquisition time would be much longer.

\section{Indication}

1. Inflammatory bowel disease; diagnosis, disease activity, prognosis, and complications.

2. "Indeterminate colitis" in children for differentiation of Crohn from ulcerative colitis.

3. For evaluation of non-IBD enteritis

4. Evaluation of polyposis syndromes and small bowel mass/tumours

5. Assessment of causes of bowel obstruction where CT and endoscopy are negative or contraindicated.

6. Assessment of coeliac disease

ACR-SAR-SPR practice parameter for the performance of MRE.

\section{Patient Preparation}

Patients are asked to avoid food $4-6 \mathrm{~h}$ before the procedure.

\section{Oral Contrast Agent}

Patients are given $1500-2000 \mathrm{ml}$ of oral contrast agent, over a period of $2 \mathrm{~h}$ before the examination.

\section{Choice of Contrast Agent}

There are three broad classifications of available oral contrast agents, biphasic, and negative and positive agents Table 1.

\section{Antispasm Agent}

To reduced artifacts due to bowel peristalsis, spasmolytic agents are helpful. Routinely glucagon is used for this purpose. ${ }^{[8]}$

\section{Contrast Agent}

It can make pathological hyper-enhancement of the bowel wall and enhancing gut lesions more prominent. ${ }^{[9]}$ Although it is not required in every case, for Crohn's disease (CD) giving IV contrast agent is recommended. Dose of gadolinium is $0.1-0.2 \mathrm{mmol} / \mathrm{kg}$ with a delay of $40-80 \mathrm{~s}$ and time to peak enhancement is typically at $60-70 \mathrm{~s}$ after IV administration.

\section{Technique}

The patient can be imaged in the supine or prone position. Axial and coronal images are taken in T1-W and T2-W image sequences Table 2. The coronal images covering most of the bowel is the most important step in acquiring the optimal quality of the scan. ${ }^{[10]}$

\section{Overview of the Protocol}

- Localizer

- Real-time two-dimensional (2D) SSFP (before glucagon)

- $\quad 0.3-0.5 \mathrm{mg}$ IV glucagon

- Axial T2-SSFSE (fat-sat)

- Coronal T2-SSFSE (without fat-sat)

- Three-dimensional (3D) SSFP

- $\quad 0.3-0.5 \mathrm{mg}$ IV glucagon

- T1W 3D-SPGR with fat-suppression

- Pre-contrast images

- IV contrast agent $0.1 \mathrm{mmol} / \mathrm{kg}$ at rate of $2 \mathrm{ml} / \mathrm{s}$ after that $25-50 \mathrm{ml}$ saline flush

- Image acquisition at $40 \mathrm{~s}$ (late arterial) and $2 \mathrm{~min}$

- T1-W axial 2D-SPGR with fat-suppression.

Total time taken during the scan is $30 \mathrm{~min}$.

\section{Clinical Application of MRE}

Literature shows that MRE is quite effective in the assessment of inflammatory bowel diseases; especially for CD. It also has an evolving role in the diagnosis of other bowel related pathologies; however, there is ongoing research to document its effectiveness in the evolution of various benign and malignant neoplasm, polyposis syndromes, various forms of enteritis, coeliac disease, and diverticular disease. ${ }^{[4-7]}$

Inflammatory bowel disease including ulcerative colitis (UC) and CD is chronic bowel pathologies with extra-luminal complications. MRE findings are similar to that of CT in most of the cases; however, with more detailed information due to the better intrinsic soft tissue contrast resolution of MR. These include wall thickening of $>3 \mathrm{~mm}$, hyper on $\mathrm{T} 2-\mathrm{W}$ and contrast enhanced and hypo on T1-W sequences, in UC circumferential with retrograde extension and CD skip lesions Fig 2. "Comb sign" and fibrofatty proliferation are seen in $\mathrm{CD}$ and "cobble-stone" appearance of mucosa is predominant in UC. ${ }^{[1]}$ 
Table 1: Contrast Agents in MRE

\begin{tabular}{l|l|l|l|l}
\hline Type & Advantages & Disadvantage & MR Appearances & Example \\
\hline Positive & Detect wall thickening & $\begin{array}{l}\text { Can obscure enhancement } \\
\text { and subtle mucosal lesions }\end{array}$ & $\begin{array}{l}\text { T1W high signal due to } \\
\text { paramagnetic effect }\end{array}$ & $\begin{array}{l}\text { Manganese chloride } \\
\text { Ferrous ammonium citrate } \\
\text { Dilute gadolinium chelates }\end{array}$ \\
\hline Negative & $\begin{array}{l}\text { Better detection of } \\
\text { bowel inflammation } \\
\text { and interloop abscesses }\end{array}$ & $\begin{array}{l}\text { Bowel wall itself is less } \\
\text { conspicuous } \\
\text { Low signal lesion cannot be } \\
\text { detected }\end{array}$ & $\begin{array}{l}\text { Short T1-W and T2-W } \\
\text { relaxation due to field } \\
\text { inhomogeneities }\end{array}$ & $\begin{array}{l}\text { SPIO } \\
\text { USPIO } \\
\text { Ferumoxsil }\end{array}$ \\
\hline Biphasic & $\begin{array}{l}\text { Better detection of } \\
\text { pathological hyper- } \\
\text { enhancement of bowel } \\
\text { wall on T1 } \\
\text { Better delineation be- } \\
\text { tween lumen and wall }\end{array}$ & & $\begin{array}{l}\text { Low signal on T1-W } \\
\text { High signal on T2-W }\end{array}$ & $\begin{array}{l}\text { Water } \\
\text { Mannitol } \\
\text { Volume } \\
\text { Polyethylene glycol } \\
\text { Methylcellulose }\end{array}$ \\
\hline
\end{tabular}

Table 2: Diagnostic Sequences in MRE

\begin{tabular}{|c|c|c|}
\hline Mandatory sequences & & Comments \\
\hline \multirow[t]{2}{*}{$\mathrm{T} 2 \mathrm{~W}$} & $\begin{array}{l}\text { Axial SSFSE/SSTSE/HASTE } \\
\text { (Fat suppressed (STIR/SPAIR) } \\
\text { Especially with bi-phasic oral contrast }\end{array}$ & $\begin{array}{l}\text { Evaluate wall inflammation and changes in } \\
\text { peri-enteric fat } \\
\text { Sensitive to flow voids } \\
\text { Limited mesenteric region information }\end{array}$ \\
\hline & $\begin{array}{l}\text { Coronal } \\
\text { SSFSE/SSTSE/HASTE } \\
\text { (without fat suppression) }\end{array}$ & Entire overview of gut to localize pathology \\
\hline \multirow[t]{2}{*}{$\mathrm{T} 1-\mathrm{W}$} & TSE/FSE & \\
\hline & 3D-SPGR & \\
\hline $\begin{array}{l}\text { Contrast enhanced } \\
\text { T1-W }\end{array}$ & $\begin{array}{l}\text { 3D-SPGR fat suppressed, venous, and } \\
\text { delayed phase }\end{array}$ & \\
\hline \multicolumn{2}{|l|}{ Optional sequences } & Comments \\
\hline DW1 & & $\begin{array}{l}\text { Shows water restriction in the inflamed wall and adja- } \\
\text { cent soft tissue }\end{array}$ \\
\hline $\begin{array}{l}\text { Quantitative perfusion } \\
\text { sequences }\end{array}$ & & $\begin{array}{l}\text { Help to differentiate between fibrosis and thickened } \\
\text { bowel wall }\end{array}$ \\
\hline
\end{tabular}

The associated complication like reactive mesenteric adenopathy is seen as T2-W hyperintense, grape-like soft tissue densities surrounded by fat Fig. 3. Similarly, fistulas are noted when two inflamed bowel walls seen opposed to each other, and in most cases, the fistulous tract is hyperintense on contrast enhanced scans and may be filled with oral contrast. Besides, associated psoas abscesses are also well visualised. ${ }^{[1]}$

Small bowel neoplasms differentiation between small benign and malignant lesions would be difficult on MRE. ${ }^{[12]}$ However, for larger lesions features such as isolated, long, and sessile lesion with mesenteric fat infiltration and associated adenopathy could indicate the presence of malignancy. ${ }^{[13]}$

Benign neoplasm includes adenoma, lipoma, and haemangioma. Adenoma is either sessile or pedunculated protruding in lumen without causing obstruction. They show homogenous enhancement on MRE. Lipoma typically presents with either bleeding or intussusception. They have characteristic MR appearance of hyperintense on T1- and T2-W with loss of signals on fat-suppressed images. Small bowel haemangiomas are difficult to distinguish from other vascular malformation on MR. 


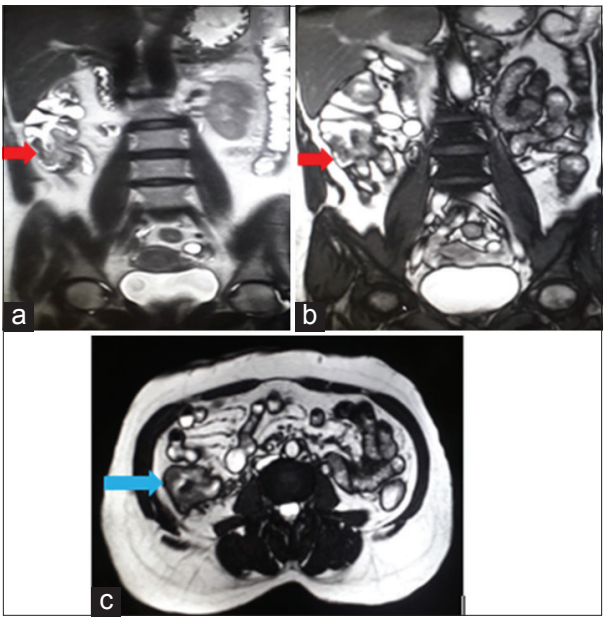

Figure 1: ( $\mathrm{a}$ and $\mathrm{b}$ ) Coronal T2-weighted magnetic resonance enterography images of a 77-year-old female patient showing low signal growth in terminal ileum extending into caecum with thickening of mucosa and narrowing the lumen (red arrows). No bowel obstruction (c) axial T2-weighted image showing similar findings (blue arrow). Biopsy of lesion proved adenocarcinoma
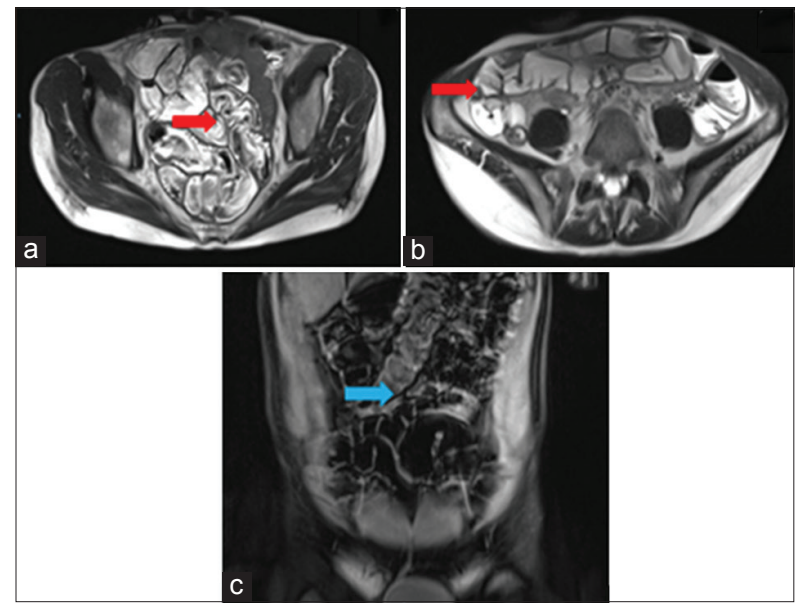

Figure 2: (a) Axial T1 post-contrast and (b) axial T2 magnetic resonance enterography (MRE) images showing long segment thickening and abnormal enhancement of small bowel in a 45-year-old female with known CD (red arrows). (c) Coronal T1 post-contrast fat-sat MRE image from a different patient showing thickening and hyperenhancement of transverse colon (blue arrow)

Polyposis syndromes include Peutz-jegher syndrome (PJ), Cowden disease, Juvenile polyposis, and gardner syndrome. PJ syndrome is associated with a high risk of malignant transformation of hamartomatous polyps which are seen throughout whole small bowel, particularly more in the jejunum. The lifetime incidence of malignancy is

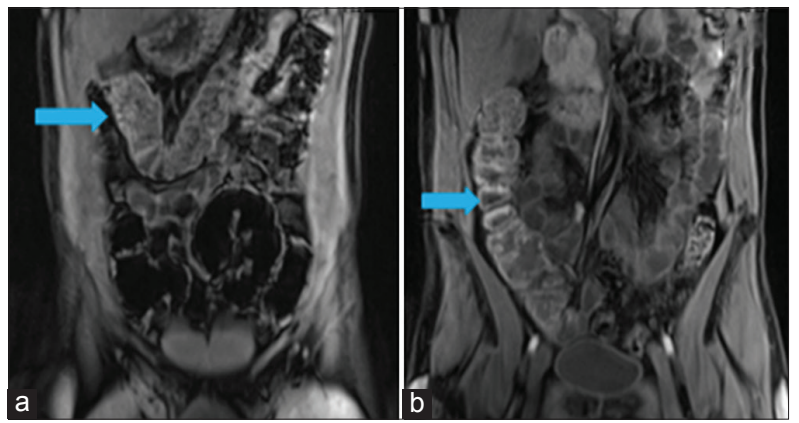

Figure 3: ( $\mathrm{a}$ and $\mathrm{b}$ ) Coronal $\mathrm{T} 1$ post-contrast fat-sat magnetic resonance enterography images from a 32-year-old male patient showing long segment enhancing large bowel loops (blue arrows) suggesting changes of ulcerative colitis

about $60 \%{ }^{\left[{ }^{[14]}\right.}$ These patients require long-term surveillance for malignancy as well as for polyp-related complications such as bleeding and intussusception. ${ }^{[15]}$ On MRE, these polyps typically appear as low signal luminal defects with marked enhancement on contrast-enhanced scans.

Adenocarcinoma is the most common malignant tumour of the gastrointestinal tract Fig 1. On MRE, it appears as circumferential or eccentric wall thickening with enhancement. Nodal and visceral metastasis can be visualised simultaneously if present. ${ }^{[16-18]}$

Carcinoid tumour is commonly seen arising from appendix or terminal ileum. It is associated with marked desmoplastic reaction around it. On MRE, these tumours appear isointense to muscles on T1-W and T2-W images having speculated margins. They have a variable appearance on MRE; such as avidly enhancing submucosal lesion, multifocal polypoidal lesions or tiny enhancing nodules carpeting the effected part of gut. ${ }^{[16]}$ They are associated with hypervascular metastases.

Lymphoma shows non-specific findings. It could present as an extra-luminal mass or circumferential wall thickening involving long segment associated with adenopathy or as aneurysmal bowel dilatation without obstruction. On post-contrast MRE sequences, they appear mildly enhancing lesions.

\section{Conclusion}

MRE is a non-invasive, multifaceted and reliable method with promising results, for small bowel pathologies. It can 
be a more reasonable alternative to CT enterography due to it can provide bowel details without the use of ionizing radiation and its ability of better soft tissue contrast resolution, especially when performed with appropriate contrast media and good bowel distension.

\section{Conflict of Interest}

The authors declare that they have no conflict of interest.

\section{References}

1. Rollandi GA, Curone PF, Biscaldi E, et al. Spiral CT of the abdomen after distention of small bowel loops with transparent enema in patients with crohn's disease. Abdom Imaging 1999;24:544-9.

2. Romano S, De Lutio E, Rollandi GA, et al. Multidetector computed tomography enteroclysis (MDCT-E) with neutral enteral and IV contrast enhancement in tumor detection. Eur Radiol 2005; 15:1178-83.

3. Jaffe TA, Gaca AM, Delaney S, et al. Radiation doses from small-bowel follow-through and abdominopelvic MDCT in crohn's disease. AJR Am J Roentgenol 2007;189:1015-22.

4. Masselli G, Picarelli A, Di Tola M, et al. Celiac disease: Evaluation with dynamic contrast-enhanced MR imaging. Radiology 2010;256:783-90.

5. Gupta A, Postgate AJ, Burling D, et al. A prospective study of MR enterography versus capsule endoscopy for the surveillance of adult patients with peutz-jeghers syndrome. AJR Am J Roentgenol 2010;195:108-16.

6. Paolantonio P, Tomei E, Rengo M, et al. Adult celiac disease: MRI findings. Abdom Imaging 2007;32:433-40.

7. Cronin CG, Lohan DG, Browne AM, et al. MR enterography in the evaluation of small bowel dilation. Clin Radiol
2009;64:1026-34.

8. Grand DJ, Beland M, Harris A. Magnetic resonance enterography. Radiol Clin North Am 2013;51:99-112.

9. Pupillo VA, Di Cesare E, Frieri G, et al. Assessment of inflammatory activity in crohn's disease by means of dynamic contrast-enhanced MRI. Radiol Med 2007;112:798-809.

10. Maccioni F, Bruni A, Viscido A, et al. MR imaging in patients with crohn disease: Value of T2-versus T1weighted gadolinium-enhanced MR sequences with use of an oral superparamagnetic contrast agent. Radiology 2006;238:517-30.

11. Chalian M, Ozturk A, Oliva-Hemker M, et al. MR enterography findings of inflammatory bowel disease in pediatric patients. AJR Am J Roentgenol 2011;196:W810-6.

12. Kamaoui I, De-Luca V, Ficarelli S, et al. Value of CT enteroclysis in suspected small-bowel carcinoid tumors. AJR Am J Roentgenol 2010;194:629-33.

13. Van Weyenberg SJ, Meijerink MR, Jacobs MA, et al. MR enteroclysis in the diagnosis of small-bowel neoplasms. Radiology 2010;254:765-73.

14. Beggs AD, Latchford AR, Vasen HF, et al. Peutz-jeghers syndrome: A systematic review and recommendations for management. Gut 2010;59:975-86.

15. Melamud K, Colip C, Soto JA. MR in the small bowel: Applications, techniques, and imaging findings. Appl Radiol 2016;45:24-6.

16. Hoeffel C, Crema MD, Belkacem A, et al. Multi-detector row CT: Spectrum of diseases involving the ileocecal area. Radiographics 2006;26:1373-90.

17. Ramachandran I, Sinha R, Rajesh A, et al. Multidetector row CT of small bowel tumours. Clin Radiol 2007;62:607-14.

18. Wiarda BM, Heine DG, Rombouts MC, et al. Jejunum abnormalities at MR enteroclysis. Eur J Radiol 2008;67:125-32. 